\section{(6) OPEN ACCESS}

\title{
After the RCT: who comes to a family-based intervention for childhood overweight or obesity when it is implemented at scale in the community?
}

\author{
James Fagg, ${ }^{1}$ Tim J Cole, ${ }^{1}$ Steven Cummins, ${ }^{2}$ Harvey Goldstein, ${ }^{1,3}$ Stephen Morris, $^{4}$ \\ Duncan Radley, ${ }^{5}$ Paul Sacher, ${ }^{6}$ Catherine Law ${ }^{1}$
}

- Additional material is published online only. To view please visit the journal online (http://dx.doi.org/10.1136/jech2014-204155).

${ }^{1}$ Centre for Paediatric Epidemiology and Biostatistics, UCL Institute of Child Health, London, UK

${ }^{2}$ Department of Social and Environmental Health Research, London School of Hygiene and Tropical Medicine, London, UK ${ }^{3}$ Centre for Multilevel

Modelling, University of Bristol, Bristol, UK

${ }^{4}$ Department of Applied Health Research, UCL, London, UK ${ }^{5}$ Carnegie Faculty, Leeds Metropolitan University, Leeds, UK

${ }^{6}$ Childhood Nutrition Research Centre, UCL Institute of Child Health, London, UK

\section{Correspondence to} Professor Catherine Law, Population, Policy \& Practice Programme, UCL Institute of Child Health, 30 Guilford Street, London WC1N 1EH, UK; Catherine.law@ucl.ac.uk

Received 12 March 2014 Revised 20 August 2014 Accepted 16 September 2014 Published Online First 7 October 2014

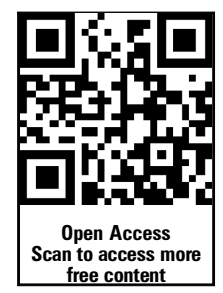

CrossMark

To cite: Fagg J, Cole TJ, Cummins $\mathrm{S}$, et al. J Epidemiol Community Health 2015;69:142-148.

\section{ABSTRACT}

Background When implemented at scale, the impact on health and health inequalities of public health interventions depends on who receives them in addition to intervention effectiveness.

Methods The MEND 7-13 (Mind, Exercise, Nutrition...Do it!) programme is a family-based weight management intervention for childhood overweight and obesity implemented at scale in the community. We compare the characteristics of children referred to the MEND programme ( $\mathrm{N}=18289$ referred to 1940 programmes) with those of the population eligible for the intervention, and assess what predicts completion of the intervention.

Results Compared to the MEND-eligible population, proportionally more children who started MEND were: obese rather than overweight excluding obese; girls; Asian; from families with a lone parent; living in less favourable socioeconomic circumstances; and living in urban rather than rural or suburban areas. Having started the programme, children were relatively less likely to complete it if they: reported 'abnormal' compared to 'normal' levels of psychological distress; were boys; were from lone parent families; lived in less favourable socioeconomic circumstances; and had participated in a relatively large MEND programme group; or where managers had run more programmes.

Conclusions The provision and/or uptake of MEND did not appear to compromise and, if anything, promoted participation of those from disadvantaged circumstances and ethnic minority groups. However, this tendency was diminished because programme completion was less likely for those living in less favourable socioeconomic circumstances. Further research should explore how completion rates of this intervention could be improved for particular groups.

\section{INTRODUCTION}

Overweight and obesity has been described as the primary childhood health problem in developed nations. ${ }^{1}$ In 2011, estimates from UK data showed that a third of children aged between 2 and 15 were overweight or obese, with prevalence among those living in the most deprived circumstances double that of those living in the least deprived. ${ }^{2}$ While prevalence may be plateauing, ${ }^{2}{ }^{3}$ the costs for children and families, health services and society remain substantial. ${ }^{4}$

Research on weight management programmes for children who are already overweight or obese has tended to focus on the effectiveness of interventions under research conditions. These studies suggest that family-based interventions may result in moderate reductions in body mass index (BMI). ${ }^{5}$ However the population impact on health and health inequalities of such interventions, when implemented at scale, depends not only on how effective the intervention itself is, but also on who receives it. ${ }^{67}$ For example, families living in more favourable socioeconomic circumstances may be more likely to access and adhere to services which support behaviour change. ${ }^{8} \quad 9$ To understand whether implementation is successful, evidence is needed about who is referred to, who starts and who completes potentially effective interventions delivered at scale in the community in relation to the population in need. ${ }^{10} 11$

Recent work mapping weight management interventions for overweight or obese children ${ }^{12}$ identified approximately 50 schemes operational around 2008 in England. In this paper we examine the largest of these schemes, MEND 7-13 (MENDMind, Exercise, Nutrition Do It!) in order to achieve two objectives: first, to explore whether the sociodemographic characteristics of MEND participants match those of the population eligible for the intervention; and second, to estimate what characteristics of children, their families and neighbourhoods are associated with completion of a MEND programme. Further objectives ${ }^{13}$ on the differential outcomes ${ }^{14}$ and economic costs of attending MEND, and its salience and acceptability to families and commissioners ${ }^{15}$ are reported elsewhere.

\section{METHODS}

\section{MEND intervention}

MEND is a multicomponent family-based community intervention which aims to support families of overweight or obese children (hereafter referred to as overweight, defined as exceeding the 91 st centile of BMI (weight/height ${ }^{2}$ ) of the UK 1990 growth charts ${ }^{16}$ ) to adopt and sustain healthier lifestyles. The intervention was demonstrated to be effective in reducing BMI of obese children after 6 and 12 months in a randomised controlled trial. ${ }^{17}$

The intervention addresses diet and physical activity through education, skills training and motivational enhancement. Owing to the importance of family involvement for behaviour change, the intervention requires a parent or carer to attend all 20 sessions and the MEND intervention was developed to be delivered in community settings such as schools or leisure centres. ${ }^{17}$ Children are eligible if they are aged between 7 and 13 years old 
and overweight although those aged $6(\mathrm{~N}=298)$ when they were referred were included in the analyses.

MEND had two operating arms in the UK: MEND Central, a limited company, and MEND Places, a not-for-profit company originally set up to provide a route for donations to subsidise places for families on the MEND programme. When the data for our study were collected, MEND Central described itself as a social enterprise-an ethical business which aims to benefit society in general. All those commissioning MEND between 2007 and 2010 placed funding through MEND Central. Families did not pay to attend the programme, places were funded by a variety of organisations including: the UK Big Lottery Fund $(n=8972)$; NHS Primary Care Trusts $(n=4373)$; non-governmental organisations $(n=617)$; and other non-profit making organisations and a private company $(n=36)$.

Between 2007 and 2010, the MEND intervention was implemented on a large scale, with programmes rolled out across all regions of England (see figure 1 for more details). Families referred to the programme contacted MEND ('referrals')whereupon MEND logged the child's age and sex, and the family postcode, collecting no other data. Families who went on to attend one or more sessions ('starters') also had sociodemographic and other data collected.

The intervention was delivered in local programmes by 'delivery partner' organisations. Intervention content and training was provided to delivery partners by MEND Central. The height, weight and psychological distress of participants were measured at the first and penultimate sessions of each MEND programme. Delivery partners were trained to measure height and weight (which was used to calculate BMI) and also recorded individual attendance of each participant at each session. Psychological distress was reported by parents using the Strengths and Difficulties Questionnaire (SDQ). ${ }^{18}$ Parents also reported the participant's ethnicity (White, Asian, Black and Other) and family socioeconomic circumstances including: family structure (lone parent/carer, couple parents/carers);

Children are eligible for MEND if they are aged 7-13 and overweight (exceeding the 91st centile of BMI of the UK 1990 growth charts). $6(n=298)$ year olds also attended and were included in the analysis

Families hear about MEND through word of mouth (for example) and then self-refer or are referred by a school nurse, paediatrician, or general practitioner (systematic data on referral not collected)

\begin{tabular}{|l|}
21,132 families contact MEND directly. MEND ask for age, sex and postcode to assign family to a \\
local programme
\end{tabular}

18,289 'referrals' with complete data on age, sex and postcode (and so all variables related to residence in LSOAs). No other data collected at this stage

\begin{tabular}{l}
$\begin{array}{l}\text { Subset of referrals (the 'starters') attend at least one MEND session and have baseline BMI } \\
\text { measurement ( } \mathrm{N}=13,998) \text {. Parents of this group fill in surveys to report information on child's } \\
\text { ethnic group, family structure, housing tenure, parental employment. Psychological and lifestyle } \\
\text { outcomes including psychological distress measured by Strengths and Difficulties Questionnaire } \\
\text { (SDQ). Attendance at each session logged by 'Delivery Partner'* staff running local MEND } \\
\text { programmes. Where data were missing for starters, values were imputed (see supplement) }\end{array}$ \\
\hline Subset of starters ('completers') attended more than $75 \%$ of sessions (N=8,311) \\
\hline
\end{tabular}

\footnotetext{
*MEND described delivery partners as including public or private leisure centres, charities such as YMCA, or housing associations employing staff trained by MEND to co-ordinate and run local MEND programmes. Staff included leisure centre managers, fitness instructors, and community activity managers knowledgeable about the practical and logistical aspects of running MEND (systematic data on staff type not collected)
}

Figure 1 Derivation of samples of MEND participants for analysis. 
housing tenure (owner occupied, social rented, private rented); and employment status of the 'primary earner' (employed, unemployed). Delivery partners recorded data in an online database collated by MEND Central. For this study, a copy of this database for the period January 2007 to December 2010 was transferred to University College London (UCL) Institute of Child Health for analysis.

The full unit postcode of each MEND participant's residential address was used to assign each address to its respective Lower Super Output Area (LSOA). Each LSOA was then linked to a measure of neighbourhood deprivation (deciles of the Income Deprivation Affecting Children Index (IDACI) 2007). ${ }^{19}$ IDACI measures the percentage of income-deprived households (those in receipt of means-tested benefits such as jobseekers allowance or child tax credits) with children aged $0-15$ in the LSOA. Deciles of the index were calculated relative to the deprivation ranking of all English LSOAs; participants in decile 10 live in the $10 \%$ most deprived areas in England. We also linked a national urban/rural status (urban, suburban, rural) classification $^{20}$ to each LSOA. MEND data were used to derive how many children attended each MEND programme (hereafter referred to as 'programme group size') and the number of programmes which a local programme manager had managed.

In the absence of an agreed definition of completion for family-based interventions for childhood overweight, ${ }^{21}$ children were considered to have completed the programme ('completers') if they had attended more than 75\% (more than 15 out of 20) of sessions.

Data were complete for BMI, postcode (and so all variables related to residence in LSOAs) and programme level variables. Starters and completers were missing data for the following variables (percentages reported for starters): baseline SDQ $(7 \%)$, ethnicity (33\%), family structure (36\%), housing tenure (35\%), employment status (63\%) and percentage of sessions attended (42\%). We followed the guidelines of Sterne et $a l^{22}$ for the analysis and reporting of missing data. Full details are given in the supplement and summarised here. First, those with complete and incomplete data were statistically different, although differences were small. Second, missingness varied between MEND programmes. Third, excluding all those with any missing data from the MEND data would have reduced the sample (and therefore the statistical power to estimate proportions) from 13998 to 2787 . To minimise bias, adjust for multilevel missingness, and maximise power, we used a multilevel multiple imputation model. The model assumed that data were missing at random; the rationale for this is described in the supplement along with the variables included in the model and the reasons for their inclusion. Ten imputed data sets were produced, analysed separately and results combined using Rubin's rules. $^{23}$ To test whether our findings were influenced by using imputed data we also conducted sensitivity analyses, including analysis using complete case data with and without the variable describing parental employment status, where missingness was particularly high.

\section{Statistical analysis}

We described the population eligible for MEND ('the MEND-eligible population') using the Health Survey for England (HSE), an annual, nationally representative cross-sectional survey of English children and adults. ${ }^{24}$ We did this by pooling the data from the 2007 to 2010 surveys for $6-13$-year-olds $(n=13468)$ who were overweight $(n=2799$, after exclusion of those where valid BMI data was missing $(n=1577)$. All analyses accounted for the HSE complex survey design and sample weights.
The sociodemographic characteristics of children participating in MEND were compared with those in the MEND-eligible population. Differences in percentages, and their statistical significance levels were calculated (MEND-eligible subtracted from MEND). The social gradient of residence by IDACI was compared graphically and tested using linear regression with an interaction term included to test the statistical significance of differences between slopes.

We estimated multilevel (participants clustered within programmes) Poisson regression models ${ }^{25}$ to assess whether completion was associated with baseline (ie, at the first session) age, sex, ethnicity, psychological distress, BMI, family structure, housing tenure, parental employment status, IDACI and urban/rural status. Unadjusted relative risks (uRR) of completion were first estimated in a set of single variable models. Where uRRs were significant at the $5 \%$ level, these variables were retained in a multivariable model to allow estimation of adjusted relative risks (aRR).

The following software was used: REALCOM-IMPUTE ${ }^{26}$ (multilevel multiple imputation model), MLwiN ${ }^{27}$ and runmlwin $^{28}$ (multilevel Poisson regression models), and Stata 12.1 (all other analyses).

Parents gave informed written consent for their child to participate in the MEND programme and for their data to be used after anonymisation. Approval for the transfer of the anonymised data from MEND to researchers at the UCL Institute of Child Health, and for the secondary analysis of these data was granted by the UCL ethics committee in October 2010 (ref 2677/002).

\section{RESULTS}

Between January 2007 and December 2010, 21132 referrals contacted MEND, 18289 of whom had complete data (see figure 1). A total of 13998 of these were starters (attended at least one session) and of these 8311 were completers (attended more than $75 \%$ of sessions).

Compared to the MEND-eligible population, proportionally more MEND referrals were girls and from urban areas while fewer were from suburban or rural areas (table 1). As would be expected, given the social gradient in childhood overweight, proportionally more of both MEND-eligible children and MEND referrals lived in more deprived compared to less deprived areas but this social gradient was significantly more pronounced for MEND referrals (test for interaction $\mathrm{p}<0.01$ : figure 2).

Compared to the MEND-eligible population, proportionally more MEND starters were: obese rather than overweight but not obese; girls; Asian; from families with a lone parent; living in social or private rented accommodation; living in a family where the primary earner was unemployed; or resident in urban areas (table 1). Proportionally fewer were children whose ethnicity was reported to be White or 'Other'. Similar sociodemographic patterns were seen in those who completed a MEND programme (table 1). Comparisons of both MEND starters and completers with the MEND-eligible population by neighbourhood deprivation deciles showed similar differences in slopes to the differences for MEND referrals (data not shown).

For sensitivity, the differences in percentages between the MEND-eligible population and MEND starters and completers were also calculated: excluding children who were 6 years old; and separately for those MEND children who were obese and for those who were overweight but not obese. Results were similar to those reported in table 1 for all MEND participants (data not shown). 
Table 1 Sociodemographic differences between the MEND-eligible population and those referred to, who start and who complete MEND

\begin{tabular}{|c|c|c|c|c|c|c|c|c|c|c|}
\hline \multirow[b]{3}{*}{ Variables } & \multirow{3}{*}{$\begin{array}{l}\text { MEND-eligible } \\
\text { population }(\mathrm{N}=2799) \%\end{array}$} & \multicolumn{9}{|c|}{ MEND participants } \\
\hline & & \multicolumn{3}{|c|}{ Referrals (N=18 289) } & \multicolumn{3}{|c|}{ Starters $(\mathrm{N}=13$ 998)* } & \multicolumn{3}{|c|}{ Completers $(\mathrm{N}=8311)^{*}$} \\
\hline & & Per cent & Diff. & ( $p$ Values) & Per cent & Diff. & (p Values) & Per cent & Diff. & ( $p$ Values) \\
\hline \multicolumn{11}{|l|}{ Adiposity } \\
\hline Overweight excl. obese & 53.8 & NA & NA & NA & 15.7 & -38.1 & $(<0.001)$ & 15.8 & -38.0 & $(<0.001)$ \\
\hline Obese & 46.2 & NA & NA & NA & 84.3 & +38.1 & $(<0.001)$ & 84.2 & +38.0 & $(<0.001)$ \\
\hline \multicolumn{11}{|l|}{ Sex } \\
\hline Boy & 53.0 & 46.7 & -6.3 & $(<0.001)$ & 45.9 & -7.1 & $(<0.001)$ & 43.4 & -9.6 & $(<0.001)$ \\
\hline Girl & 47.0 & 53.3 & +6.3 & $(<0.001)$ & 54.1 & +7.1 & $(<0.001)$ & 56.6 & +9.6 & $(<0.001)$ \\
\hline \multicolumn{11}{|l|}{ Ethnicity } \\
\hline White & 79.6 & NA & NA & NA & 77.3 & -2.3 & $(0.01)$ & 78.5 & -1.1 & $(0.3)$ \\
\hline Asian & 10.0 & NA & NA & NA & 13.0 & +3.0 & $(<0.001)$ & 12.4 & +2.4 & $(<0.003)$ \\
\hline Black & 5.7 & NA & NA & NA & 5.9 & +0.2 & $(0.6)$ & 5.5 & -0.2 & $(0.6)$ \\
\hline Other & 4.7 & NA & NA & NA & 3.8 & -0.9 & $(<0.03)$ & 3.6 & -1.1 & $(0.02)$ \\
\hline \multicolumn{11}{|l|}{ Family structure } \\
\hline Lone parent & 30.5 & NA & NA & NA & 34.5 & +4.0 & $(0.02)$ & 31.5 & +1.0 & $(0.6)$ \\
\hline Couple & 69.5 & NA & NA & NA & 65.5 & -4.0 & $(0.02)$ & 68.5 & -1.0 & $(0.6)$ \\
\hline \multicolumn{11}{|l|}{ Housing tenure } \\
\hline Owned & 63.5 & NA & NA & NA & 53.4 & -10.1 & $(<0.001)$ & 58.2 & -5.3 & $(<0.001)$ \\
\hline Social & 25.2 & NA & NA & NA & 31.9 & +6.7 & $(<0.001)$ & 27.9 & +2.7 & $(0.009)$ \\
\hline Private & 11.3 & NA & NA & NA & 14.7 & +3.4 & $(<0.001)$ & 13.9 & +2.6 & $(0.001)$ \\
\hline \multicolumn{11}{|l|}{ Employment status } \\
\hline Employed & 79.4 & NA & NA & NA & 73.9 & -5.5 & $(<0.001)$ & 77.2 & -2.2 & $(0.04)$ \\
\hline Unemployed & 20.6 & NA & NA & NA & 26.1 & +5.5 & $(<0.001)$ & 22.8 & +2.2 & $(0.04)$ \\
\hline \multicolumn{11}{|l|}{ Urban/rural } \\
\hline Urban & 82.1 & 89.2 & +7.1 & $(<0.001)$ & 89.0 & +6.9 & $(<0.001)$ & 88.1 & +6.0 & $(<0.001)$ \\
\hline Suburban & 8.9 & 6.4 & -2.5 & $(<0.001)$ & 6.4 & -2.5 & $(<0.001)$ & 7.0 & -1.9 & $(0.001)$ \\
\hline Rural & 9.0 & 4.6 & -4.4 & $(<0.001)$ & 4.5 & -4.5 & $(<0.001)$ & 4.9 & -4.1 & $(<0.001)$ \\
\hline
\end{tabular}

Single (unadjusted) variable models showed that, having started a MEND programme, completion was significantly associated with psychological distress at baseline, sex, family structure, housing tenure, employment status, IDACI 2007,

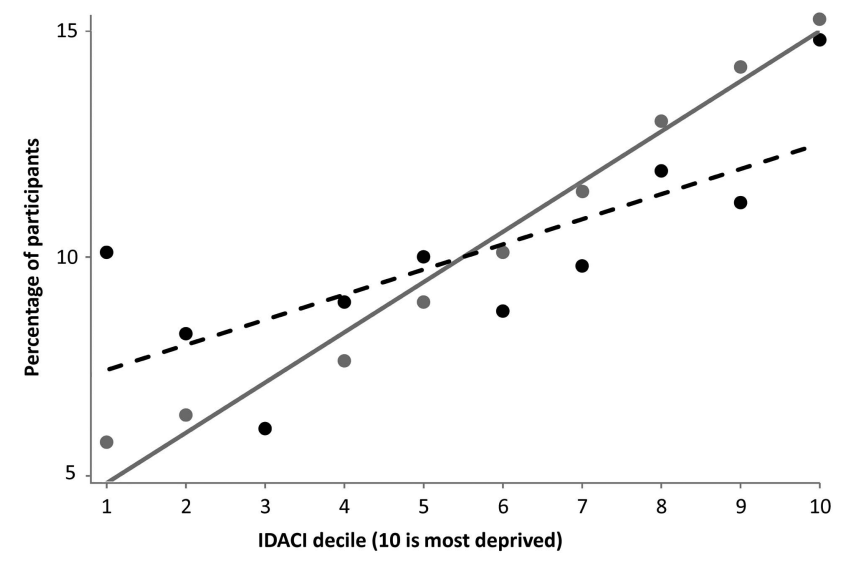

Figure 2 Social gradients of those referred to Mind, Exercise, Nutrition Do It! (MEND; grey dots and line) and MEND-eligible population (black dots and dashed line) by IDACI 2007 (neighbourhood deprivation) deciles. Trends were tested for differences $(p<0.001)$. IDACl, Income Deprivation Affecting Children Index. programme group size and the number of programmes per manager (see uRR in table 2). These variables were retained in the multivariable model. Age, baseline BMI, ethnicity and urban/rural status were not significantly associated and therefore not retained.

In the multivariable model, the aRR (see aRR in table 2) showed that children who had started a MEND programme were significantly less likely to complete it if they: were reported by parents as having 'abnormal' rather than 'normal' levels of psychological distress; were boys; were from lone parent rather than couple parent families; lived in social or private rented rather than owner occupied accommodation; lived in a family where the primary earner was unemployed rather than employed; were resident in LSOAs in more deprived IDACI 2007 deciles rather than less deprived; participated in a relatively large MEND programme group; or participated in a programme led by a manager who had run a relatively high number of programmes.

In the absence of an agreed definition of completion we re-estimated the multivariable model with completion defined as attending more than $60 \%$ of sessions. Findings were similar to those observed for completion defined as attendance at more than $75 \%$ of sessions (data not shown).

We repeated all analyses with complete case data to test sensitivity of findings to imputation and specifically to the high proportion of missing data on employment status. Findings were 
Table 2 Unadjusted (URR) and adjusted relative risks (aRR) of completion of a MEND programme by sociodemographic characteristics of participants ( $\mathrm{N}=13$ 998)

\begin{tabular}{|c|c|c|}
\hline Parameters & $\begin{array}{l}\text { Single variable models } \\
\text { uRR }(95 \% \mathrm{Cl})\end{array}$ & $\begin{array}{l}\text { Multivariable model } \\
\text { aRR }(95 \% \mathrm{Cl})\end{array}$ \\
\hline Intercept & - & $0.85(0.76 \text { to } 0.95)^{* *}$ \\
\hline \multicolumn{3}{|c|}{ BMI baseline (ref. 91st-95th centile) } \\
\hline 95th-98th centile & 1.02 (0.91 to 1.14$)$ & - \\
\hline Greater than 98th centile & $1.00(0.92$ to 1.10$)$ & - \\
\hline \multicolumn{3}{|l|}{ SDQ baseline (ref. 'Normal') } \\
\hline 'Borderline' & 0.95 (0.89 to 1.02$)$ & 0.97 (0.90 to 1.04$)$ \\
\hline 'Abnormal' & $0.88(0.83 \text { to } 0.93)^{* * *}$ & $0.91(0.86 \text { to } 0.97)^{* *}$ \\
\hline Age (years) & $0.99(0.97$ to 1.00$)$ & \\
\hline \multicolumn{3}{|l|}{ Sex (ref. Girls) } \\
\hline Boys & $0.90(0.86 \text { to } 0.95)^{* * *}$ & $0.91(0.87 \text { to } 0.96)^{* * *}$ \\
\hline \multicolumn{3}{|l|}{ Ethnicity (ref. White) } \\
\hline Asian & $0.94(0.87$ to 1.00$)$ & - \\
\hline Black & $0.91(0.82$ to 1.00$)$ & - \\
\hline Other & $0.94(0.83$ to 1.08$)$ & - \\
\hline \multicolumn{3}{|l|}{ Family structure (ref. couple) } \\
\hline Lone parent & $0.87(0.82 \text { to } 0.92)^{* * *}$ & $0.93(0.88 \text { to } 0.98)^{*}$ \\
\hline \multicolumn{3}{|c|}{ Housing tenure (ref. Owner occupied) } \\
\hline Social rented & $0.80(0.75 \text { to } 0.85)^{* * *}$ & $0.88(0.82 \text { to } 0.95)^{* * *}$ \\
\hline Private rented & $0.86(0.80 \text { to } 0.92)^{* * *}$ & $0.90(0.84 \text { to } 0.97)^{* *}$ \\
\hline \multicolumn{3}{|c|}{ Employment status (ref. Employed) } \\
\hline Unemployed & $0.84(0.79 \text { to } 0.89)^{* * *}$ & $0.93(0.87 \text { to } 0.98)^{*}$ \\
\hline \multicolumn{3}{|c|}{ IDACI 2007 deciles (ref. Decile 1, least deprived) } \\
\hline 2 & 1.00 (0.88 to 1.14$)$ & $1.01(0.89$ to 1.15$)$ \\
\hline 3 & 0.97 (0.86 to 1.09$)$ & 0.99 (0.88 to 1.12$)$ \\
\hline 4 & 0.95 (0.84 to 1.08$)$ & $0.98(0.87$ to 1.11$)$ \\
\hline 5 & $0.92(0.82$ to 1.04$)$ & $0.96(0.84$ to 1.08$)$ \\
\hline 6 & $0.87(0.78 \text { to } 0.97)^{*}$ & $0.92(0.82$ to 1.03$)$ \\
\hline 7 & $0.86(0.77 \text { to } 0.97)^{*}$ & $0.93(0.82$ to 1.04$)$ \\
\hline 8 & $0.84(0.75 \text { to } 0.95)^{* *}$ & $0.93(0.82$ to 1.05$)$ \\
\hline 9 & $0.81(0.73 \text { to } 0.91)^{* * *}$ & 0.91 (0.80 to 1.02$)$ \\
\hline 10—most deprived & $0.74(0.66 \text { to } 0.83)^{* * *}$ & $0.85(0.76 \text { to } 0.96)^{* *}$ \\
\hline \multicolumn{3}{|c|}{ Urban/rural status (ref. Urban) } \\
\hline Suburban & 1.09 (1.00 to 1.20$)$ & - \\
\hline Rural & 1.10 (0.98 to 1.22$)$ & - \\
\hline \multicolumn{3}{|c|}{ Programme group size (ref. 1-5) } \\
\hline $6-9$ & $0.93(0.86$ to 1.01$)$ & 0.93 (0.86 to 1.01$)$ \\
\hline 10 or more & $0.83(0.76 \text { to } 0.90)^{* * *}$ & $0.84(0.77 \text { to } 0.91)^{* * *}$ \\
\hline \multicolumn{3}{|c|}{ Number of programmes per manager (ref. less than 10) } \\
\hline 10 or more & $0.91(0.85 \text { to } 0.98)^{*}$ & $0.93(0.86 \text { to } 0.99)^{*}$ \\
\hline
\end{tabular}

similar to those using imputed data (see online supplementary section G12).

\section{DISCUSSION}

Our results showed that in comparison to the MEND-eligible population, proportionally more children who started or completed MEND lived in less favourable socioeconomic circumstances (indicated by employment of primary earner, family structure and housing tenure). Relative to the MEND-eligible population, proportionally more of those who started or completed a MEND programme were girls, Asian and urban dwelling and proportionally fewer were of White or 'Other' ethnicity. Finally, relative to the MEND-eligible population, proportionally more MEND participants were obese rather than overweight but not obese. These differences may have arisen from differential uptake or differential provision of MEND but we did not have data to investigate this further.

In contrast, for those who started a MEND programme, those living in less favourable socioeconomic circumstances were less likely to complete it, as were boys and those reporting 'abnormal' levels of psychological distress at baseline. Completion of a MEND programme was also less likely if the programme group size was relatively high and if the programme manager was more experienced. Completion was not associated with baseline BMI, age or ethnic group. However, these relative differences in completion rates were not sufficient to remove the tendency for starters and completers overall to be less advantaged than the MEND-eligible population.

\section{STRENGTHS AND LIMITATIONS}

We used data from a family-based intervention for childhood overweight which had been implemented at scale in the community. This was an unusual opportunity to assess how an intervention which has been found to be effective in a research setting is provided and accessed in the 'real world'. In addition, the large scale implementation meant that the data set was sufficiently large to precisely estimate proportions for each sociodemographic group and factors associated with predictors of completion of the programme. The MEND data were collected for service rather than research purposes and, as is common in service data, data quality was variable, with considerable missing data. We carried out extensive data cleaning procedures to maximise the quality of the data that we analysed. We also used imputed data obtained from a multilevel multiple imputation model to mitigate systematic bias and increase the precision of estimates. We also ran analyses with both complete case and imputed analyses to show that the overall conclusions we drew were the same.

We used a robust, nationally representative survey (HSE) to estimate the population of children in England who would theoretically be eligible for the MEND intervention, and compare the characteristics of this population 'in need' with those who were referred to, started or completed a MEND programme. The lone parent and employment status variables were not coded identically in MEND and the HSE. However, our results using the lone parent and employment variables were consistent with those using the IDACI 2007 measure which was standard in both MEND and HSE data sets.

We repeated our HSE-MEND comparison, substituting two other contemporaneous nationally representative data sets in turn in the place of the HSE. The Millennium Cohort Study sweep four ${ }^{29}$ was nationally representative for overweight children in England aged 6-8 years old in 2008 and, when compared to MEND participants of the same age, findings were similar to the HSE-MEND comparison (eg, proportionally more children living in less favourable circumstances among the MEND participants than in the Millennium Cohort). The National Child Measurement Programme ${ }^{30}$ was nationally representative for overweight children in England in school year 10 (10-11 years old) in the years 2007-2010 and, when compared to MEND children of the same age, findings were again similar to the HSE-MEND comparison. These sensitivity analyses (data not shown) showed that our findings were robust to how we assessed the population who would be eligible for MEND.

\section{COMPARISON WITH OTHER STUDIES}

Differential provision or uptake of interventions both have the potential to generate, maintain, widen or decrease health 
inequalities. ${ }^{7}{ }^{8}$ We found no research which compared the sociodemographic characteristics of participants in a familybased community intervention for childhood overweight with the population in need, although a similar analysis has been outlined in an evaluation framework for an Australian weight management scheme for adults. ${ }^{31}$ Our findings that the sociodemographic characteristics of MEND participants marginally over-represent families living in more deprived areas are consistent with previous work on smoking cessation ${ }^{6}$ and coronary heart disease treatment. ${ }^{32}$ However, we are not aware of similar work in services for children's health.

Relatively few published studies have considered who 'drops out' or completes children's weight management interventions, and a review of this work suggests that study designs (including intervention type) and findings are heterogeneous and typically based in research or clinical settings. ${ }^{33}$ This study adds to this evidence base because it was based on a large data set who received a family-based community intervention for childhood overweight following implementation at scale in the community (as opposed to in a research setting).

Consistent with smaller scale studies of attrition in paediatric weight management interventions delivered predominantly in clinical settings, we found that completion was less likely among participants living in less favourable socioeconomic circumstances. ${ }^{34} 35$ No families had to pay for the MEND programme and so direct financial costs of participation would not explain differential completion by socioeconomic status. However, indirect costs of participation to families and the amount of time available to parents to take children to programmes may have explained some of these differences. ${ }^{33}$ This reinforces concerns that the acceptability of, or adherence to, services is worse for those from less advantaged circumstances and may indicate that services still need to develop and adapt to meet the needs of these families.

\section{CONCLUSIONS}

The provision and/or uptake of MEND did not appear to compromise and, if anything, promoted participation of those from more disadvantaged circumstances and from ethnic minority groups. This suggests that participation in MEND, when it was implemented at scale across England, had the potential to make a contribution to tackling health inequalities. However, this potential was diminished to some extent because; having started a programme, completion was relatively less likely for those participants living in less favourable socioeconomic circumstances. It was also less likely for boys. Further research should explore why this occurs, and investigate how completion rates could be improved for these groups. Approaches to this may include using survival analysis to examine critical points where exit from the programme is more likely.

MEND programmes have been implemented across a number of income rich countries beyond England, including Wales, Denmark, Australia, New Zealand, USA and Canada and so the results from this study may be generalisable to these countries. We do not know to what extent our findings are generalisable to other weight management or community interventions. Assessment of the reach of interventions (of any kind) when implemented at scale is likely to be based on service or routine data, and such data are likely to have higher levels of missingness than research data. We hope that the publication of these findings will stimulate further exploration of such data to determine what happens when research is put into practice in community settings.

\section{What is already known on this subject}

- Differential referral to, participation in and completion of interventions have the potential to generate, maintain, decrease or widen inequalities in health.

- Childhood overweight and obesity are already socially patterned so the potential for interventions to widen inequalities is of particular concern.

- The sociodemographic characteristics of participants in weight management randomised controlled trials may not reflect those of the population who would be eligible for the intervention if it was implemented at scale.

\section{What this study adds}

- Compared to those eligible for the intervention, proportionally more girls, children who lived in less favourable socioeconomic circumstances and Asian children started and completed Mind, Exercise, Nutrition Do It! (MEND).

- In contrast, having started a MEND programme, children were relatively less likely to complete it if they lived in less favourable socioeconomic circumstances and were boys. There were no differences in completion by ethnic group.

- Participation in MEND, when it was implemented at scale across England, had the potential to make a contribution to tackling health inequalities. However, this potential was diminished to some extent because, having started a programme, completion was relatively less likely for participants living in less favourable socioeconomic circumstances.

Acknowledgements The authors would like to thank colleagues at the National Centre for Social Research (NatCen) who assisted by linking in neighbourhood data and BMI zscore data to the Health Survey for England. Colleagues at NatCen also provided syntax for deriving variables to describe lone and couple parent families and to adjust for the design of the survey. Colleagues at the Centre for Longitudinal Studies (Institute of Education, University of London) who assisted by linking in neighbourhood data to the fourth sweep of the Millennium Cohort Study (MCS). Colleagues at the National Obesity Observatory (NOO) who assisted with analysis of the National Child Measurement Programme (NCMP).

Contributors CL, SC, TJC, SM and PS conceived the study and all authors contributed to study design. JF analysed data, interpreted results and drafted the manuscript. TJC and HG advised on aspects of the data analysis. All authors interpreted results and commented on drafts of the manuscript. CL is guarantor.

Funding This paper presents independent research funded by the National Institute for Health Research (NIHR) (PHR-09/2005/05). The views expressed are those of the author(s) and not necessarily those of the NHS, the NIHR or the Department of Health. The NIHR had no role in study design, and the collection, analysis, and interpretation of data, and the writing of the article or the decision to submit it for publication. The Centre for Paediatric Epidemiology and Biostatistics was supported in part by the Medical Research Council in its capacity as the MRC Centre of Epidemiology for Child Health (award G0 400 546). Research at the University College London Institute of Child Health and Great Ormond Street Hospital for Children receives a proportion of the funding from the Department of Health's National Institute for Health Research Biomedical Research Centres funding scheme, Department of Health-National Institute for Health Research-Health Services and Delivery Research (HS \& DR) Programme PHR—09/3005/05.

Competing interests SC is supported by an NIHR Senior Fellowship. TJC is funded by MRC Research Grant MR/J004389/1. DR and PS were employees of MEND Central during the project, and PS was a shareholder in MEND Central. PS was also one of the developers of the MEND intervention. Given that results from the project might support, threaten or have no effect on MEND Central's success, our grant application to NIHR and subsequent protocol set out governance measures 
to ensure that competing interests, and the interests of project stakeholders, were managed appropriately. As part of these measures PS and DR had no access to data and no role in analyses. All authors have completed the ICMJE uniform disclosure form (available on request from the corresponding author).

Ethics approval UCL ethics committee.

Provenance and peer review Not commissioned; externally peer reviewed.

Open Access This is an Open Access article distributed in accordance with the terms of the Creative Commons Attribution (CC BY 4.0) license, which permits others to distribute, remix, adapt and build upon this work, for commercial use, provided the original work is properly cited. See: http://creativecommons.org/ licenses/by/4.0/

\section{REFERENCES}

1 Ebbeling CB, Pawlak DB, Ludwig DS. Childhood obesity: public-health crisis, common sense cure. Lancet 2002;360:473-82

2 Mandalia D. Children's BMI, overweight and obesity. In: Craig R, Mindell J, eds. Health Survey for England 2011: health, social care and lifestyles. London: The Health and Social Care Information Centre, 2012:363-75.

3 Olds T, Maher C, Zumin S, et al. Evidence that the prevalence of childhood overweight is plateauing: data from nine countries. Int J Pediatr Obes 2011;6:342-60.

4 Butland B, Jebb S, Kopelman P, et al. Foresight. Tackling obesities: future choicesproject report. UK: Government Office for Science, 2007.

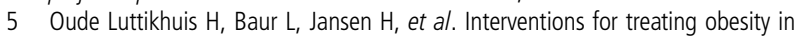
children. Cochrane Database Syst Rev 2009;(1):CD001872.

6 Bauld L, Judge K, Platt S. Assessing the impact of smoking cessation services on reducing health inequalities in England: observational study. Tob Control 2007;16:400-4.

7 Lorenc $T$, Petticrew $M$, Welch $V$, et al. What types of interventions generate inequalities? Evidence from systematic reviews. J Epidemiol Community Health 2013;67:190-3.

8 Shrewsbury V, Wardle J. Socioeconomic status and adiposity in childhood: a systematic review of cross-sectional studies 1990-2005. Obesity 2008;16:275-84.

9 Zeller M, Kirk S, Claytor R, et al. Predictors of attrition from a pediatric weight management program. J Pediatr 2004;144:466-70.

10 Edwards N. Scaling-up health innovations and interventions in public health: a brief review of the current state-of-the-science. Proceedings of the Inaugural Conference to Advance the State of the Science and Practice on Scale-up and Spread of Effective Health Programs; July 6-8 2010, Washington, DC.

11 Glasgow RE, Vogt TM, Boles SM. Evaluating the public health impact of health promotion interventions: the RE-AIM framework. Am J Public Health 1999:89:1322-7.

12 Aicken C, Roberts $H$, Arai L. Mapping service activity: the example of childhood obesity schemes in England. BMC Public Health 2010;10:310-16.

13 Law C. A population-level evaluation of a family-based community intervention for childhood overweight and obesity: protocol for funded project. National Institute for Health Research Public Health Research Programme, 2010. http://www.nets.nihr.ac. uk/projects/phr/09300505 (accessed 18 Mar 2013).

14 Fagg J, Chadwick P, Cole TJ, et al. From trial to population: a study of a family-based community intervention for childhood overweight implemented at scale. Int J Obes 2014.

15 Lucas P, Curtis-Tyler K, Arai L, et al. What works in practice: user and provider perspectives on the acceptability, affordability, implementation, and impact of a family-based intervention for child overweight and obesity delivered at scale. BMC Public Health 2014;14:614.

16 Cole TJ, Freeman JV, Preece MA. Body mass index reference curves for the UK, 1990. Arch Dis Child 1995;73:259.

17 Sacher PM, Kolotourou M, Chadwick PM, et al. Randomized controlled trial of the MEND program: a family-based community intervention for childhood obesity. Obesity 2010;18(Suppl 1):S62-8.

18 Goodman R. The strengths and difficulties questionnaire: a research note. J Child Psychol Psychiat 1997;38:581-6.

19 Noble M, McLennan D, Wilkinson K, et al. English indices of deprivation 2007. London: Communities and Local Government, 2008.

20 Bibby P, Shephard J. Developing a new classification of urban and rural areas for policy purposes - the methodology. London, Department for Environment, Food and Rural Affairs, 2004.

21 National Institute for Health and Clinical Excellence. Public Health Guidance Scope. http://www.nice.org.uk/nicemedia/live/13506/58797/58797.pdf2012 (accessed 18 Mar 2013).

22 Sterne JAC, White IR, Carlin JB, et al. Multiple imputation for missing data in epidemiological and clinical research: potential and pitfalls. BMJ 2009;339: 157-60.

23 Rubin DB. Multiple imputation for nonresponse in surveys. USA: John Wiley and Sons, 1987

24 Aresu M, Becares L, Brage S, et al. Health survey for England 2008: volume 1. Physical activity and fitness. Leeds: NHS Information Centre, 2009. https://catalogue. ic.nhs.uk/publications/public-health/surveys/heal-surv-phys-acti-fitn-eng-2008/ heal-surv-phys-acti-fitn-eng-2008-rep-v2.pdf (accessed 18 Mar 2013).

25 Zou G. A modified poisson regression approach to prospective studies with binary data. Am J Epidemiol 2004;159:702-6.

26 Carpenter JR, Goldstein H, Kenwood MG. REALCOM-IMPUTE software for multilevel multiple imputation with mixed response types. J Stat Software 2011:45:1-14.

27 Rasbash J, Charlton C, Browne WJ, et al. MLwiN Version 2.1. Centre for Multilevel Modelling, University of Bristol, 2009.

28 Leckie G, Charlton C. runm/win: Stata module for fitting multilevel models in the MLwiN software package. Bristol: Centre for Multilevel Modelling, University of Bristol, 2011.

29 Centre for Longitudinal Studies. Welcome to the Millennium Cohort Study. http:// www.cls.ioe.ac.uk/page.aspx?\&sitesectionid $=851$ \&sitesectiontitle=Welcome+to+the +Millennium+Cohort+Study (accessed 20 Mar 2013).

30 NHS Information Centre. National Child Measurement Programme. http://www.ic. nhs.uk/ncmp (accessed 20 Mar 2013).

31 O'Hara BJ, Bauman AE, Eakin EG, et al. Evaluation framework for translational research. Health Promot Pract 2013;14:380-9.

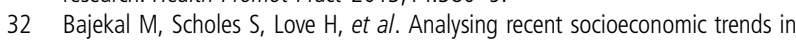
coronary heart disease mortality in England, 2000-2007: a population modelling study. PLoS Med 2012;9:12.

33 Skelton JA, Beech BM. Attrition in paediatric weight management: a review of the literature and new directions. Obes Rev 2011;12:e273-81.

34 de Niet J, Timman $\mathrm{R}$, Jongejan $\mathrm{M}$, et al. Predictors of participant dropout at various stages of a pediatric lifestyle program. Pediatrics 2011;127:e164-70.

35 Welsby D, Nguyen B, O'Hara B, et al. Process evaluation of an up-scaled community based child obesity treatment program: NSW Go4Fun(R). BMC Public Health 2014;14:140. 